\title{
QUEEN'S
UNIVERSITY
BELFAST
}

\section{Homocysteine, Methylenetetrahydrofolate Reductase C677T Polymorphism, and Risk of Retnal Vein Occlusion: A Meta-analysis}

\author{
McGimpsey, S. J., Woodside, J. V., Cardwell, C., Cahill, M., \& Chakravarthy, U. (2009). Homocysteine, \\ Methylenetetrahydrofolate Reductase C677T Polymorphism, and Risk of Retnal Vein Occlusion: A Meta- \\ analysis. Ophthalmology, 116(9), 1778-1787. https://doi.org/10.1016/j.ophtha.2009.02.033
}

Published in:

Ophthalmology

Queen's University Belfast - Research Portal:

Link to publication record in Queen's University Belfast Research Portal

\section{General rights}

Copyright for the publications made accessible via the Queen's University Belfast Research Portal is retained by the author(s) and / or other copyright owners and it is a condition of accessing these publications that users recognise and abide by the legal requirements associated with these rights.

Take down policy

The Research Portal is Queen's institutional repository that provides access to Queen's research output. Every effort has been made to ensure that content in the Research Portal does not infringe any person's rights, or applicable UK laws. If you discover content in the Research Portal that you believe breaches copyright or violates any law, please contact openaccess@qub.ac.uk. 


\section{Homocysteine, Methylenetetrahydrofolate Reductase C677T Polymorphism, and Risk of Retinal Vein Occlusion: A Meta-analysis}

Stuart J. McGimpsey, MB, MRCOphth, ${ }^{1}$ Jayne V. Woodside, MA (Hons), PhD, ${ }^{2}$ Chris Cardwell, PhD, ${ }^{2}$ Mark Cahill, FRCSI, FRCOphth, ${ }^{3}$ Usha Chakravarthy, $\mathrm{MD}, \mathrm{PhD}^{1,4}$

Objective: To assess the role of plasma total homocysteine (tHcy) concentrations and homozygosity for the thermolabile variant of the methylenetetrahydrofolate reductase (MTHFR) C677T gene as risk factors for retinal vascular occlusive disease.

Design: Retinal vein occlusion (RVO) is an important cause of vision loss. Early meta-analyses showed that tHcy was associated with an increased risk of RVO, but a significant number of new studies have been published.

Participants and/or Controls: RVO patients and controls.

Methods: Data sources included MEDLINE, Web of Science, and PubMed searches and searching reference lists of relevant articles and reviews. Reviewers searched the databases, selected the studies, and then extracted data. Results were pooled quantitatively using meta-analytic methods.

Main Outcome Measures: tHcy concentrations and MTHFR genotype.

Results: There were 25 case-control studies for tHcy (1533 cases and 1708 controls) and 18 case-control studies for MTHFR (1082 cases and 4706 controls). The mean tHcy was on average $2.8 \mu \mathrm{mol} / \mathrm{L}$ ( $95 \%$ confidence interval [Cl], 1.8-3.7) greater in the RVO cases compared with controls, but there was evidence of between-study heterogeneity $\left(P<0.001, \mathrm{I}^{2}=93 \%\right)$. There was funnel plot asymmetry suggesting publication bias. There was no evidence of association between homozygosity for the MTHFR C677T genotype and RVO (odds ratio [OR] 1.20; $95 \% \mathrm{Cl}, 0.84-1.71)$, but again marked heterogeneity $\left(P=0.004, \mathrm{I}^{2}=53 \%\right)$ was observed.

Conclusions: There was some evidence that elevated tHcy was associated with RVO, but not homozygosity for the MTHFR C677T genotype. Both analyses should be interpreted cautiously because of marked heterogeneity between the study estimates and possible effect of publication bias on the thcy findings.

Financial Disclosure(s): The author(s) have no proprietary or commercial interest in any materials discussed in this article. Ophthalmology 2009;116:1778-1787 () 2009 by the American Academy of Ophthalmology.

Retinal vein occlusion (RVO) is an important cause of vision $\operatorname{loss}^{1,2}$ and has been linked to an increased risk of cardiovascular mortality and stroke. ${ }^{3-5}$ Central RVO, even when unilateral, may be associated with reduced visionrelated quality of life. ${ }^{6}$ It has been hypothesized that elevated total plasma homocysteine (tHcy) is a risk factor in $\mathrm{RVO},{ }^{7}$ as in atherosclerotic disease. ${ }^{8,9}$ Although elevated tHcy has been implicated in vascular occlusions in the retina, a number of studies have failed to demonstrate such a relationship. ${ }^{10-12}$

Homocysteine, a sulphur-containing amino acid, is an intermediary product in methionine metabolism. ${ }^{13}$ It is metabolized by 2 major pathways. When methionine is in excess, tHcy follows the transsulphuration pathway, where it is irreversibly conjugated to serine by cystathionine $\beta$-synthase in a process requiring vitamin $\mathrm{B}_{6}$ as a cofactor. Under conditions of low methionine, tHcy is primarily metabolized through the methionine-conserving remethylation pathway. In most tissues, tHcy is remethylated in a process requiring methionine synthase, vitamin $\mathrm{B}_{12}$ as co- factor, and methyltetrahydrofolate as cosubstrate. The pathway requires the enzyme methylene tetrahydrofolate reductase (MTHFR) and an adequate supply of folic acid. Genetic and acquired abnormalities in the function of any of these enzymes or deficiencies in folic acid, vitamin $\mathrm{B}_{6}$, or vitamin $\mathrm{B}_{12}$ cofactors can lead to elevated tHcy levels. ${ }^{13}$ One important cause of elevated tHcy is a polymorphism in the MTHFR C677T gene, which is common in Western populations $(10 \%-15 \%$ of individuals homozygous for this polymorphism). ${ }^{14,15}$ Individuals homozygous for the thermolabile TT variant of MTHFR show greater levels of tHcy, particularly when serum folate levels are low. ${ }^{14,15}$

Two meta-analyses ${ }^{7,16}$ that were previously performed concluded that elevated plasma tHcy was probably associated with RVO. Neither of these meta-analyses revealed a significant association between the thermolabile TT genotype and RVO risk. ${ }^{7,16}$ Because there has been a significant number of further studies published, ${ }^{10-12,17-24}$ we undertook an updated meta-analysis of published data on the relationships among tHcy, MTHFR C677T polymorphism, and RVO. The finding 
of a conclusive link between tHcy and RVO risk could lead to preventative measures because folic acid supplementation can reduce serum tHcy levels ${ }^{25}$ even in those with the thermolabile MTHFR C677T polymorphism. ${ }^{26}$

\section{Materials and Methods}

\section{Search Strategy and Data Extraction}

Eligible studies were identified by searching MEDLINE through OVID ONLINE using this strategy ("explode 'Retinal Vein Occlusion'/all subheadings") and ("explode 'homocysteine' or 'homocysteine' keyword") or ("explode 'MTHFR' or 'MTHFR' keyword"). A similar strategy was used in searches on Web of Science and PubMed. On each database, the search was limited to studies on humans published up to and including October 2007.

Abstracts were screened independently by 2 investigators (SMcG, JW) to establish whether studies were likely to provide relevant data based on the following criteria: (1) included laboratory assessment of serum or plasma tHcy concentrations; or (2) assessed the C677T MTHFR polymorphism; and (3) compared human subjects with and without RVO.

If abstracts were considered relevant, full articles were obtained and examined. The reference lists of all relevant articles were reviewed for citations to articles.

Eligible studies were assessed independently by 3 reviewers (SMcG, JVW, CC) using a structured form to extract information about the study (country and year of publication), study subjects (number of cases and controls, selection of cases and controls, age), and tHcy and MTHFR data. A number of possible indicators of study quality were also extracted, including closeness of agematching of cases and controls, use of fasting glucose samples, and pre-statement of exclusion criteria. The extracted datasets were cross-checked before analysis was performed.

Initially, corresponding authors from each study were contacted to ask for the original dataset used for study analysis, but this approach had limited success, because the investigators either did not respond to our requests for data or were unable to provide access to original datasets.

\section{Statistical Methods}

Homocysteine. The difference in mean tHcy between the RVO and control groups and $95 \%$ confidence intervals were calculated for each study. In 3 studies, ${ }^{17,27,28}$ the mean and standard deviation were estimated from formulae using the median and range. ${ }^{29} \mathrm{In}$ one study, ${ }^{30}$ the mean and standard deviation were estimated from formulae using the median and interquartile range. ${ }^{31}$ In another study, ${ }^{32}$ the standard deviation estimates were not available within groups, so the standard error of the difference in means was estimated from the $P$ value of a $t$ test. ${ }^{33}$

Because the distribution of tHcy is typically slightly skewed, sensitivity analyses were conducted on log-transformed data where patient-level data were available, and including only those studies with more than 35 patients in each group (in which non-normality would be less problematic). An additional sensitivity analysis was conducted removing studies for which formulae were applied to calculate the mean and standard deviations.

Methylenetetrahydrofolate Reductase. Odds ratios (OR) and 95\% CIs were calculated for the MTHFR TT genotype exposure and RVO. In one study, ${ }^{34}$ no TT genotype was observed in the $\mathrm{RVO}$ group, so a correction was added to provide an estimate of the $\mathrm{OR}^{35}$ and standard error.

The $\mathrm{I}^{2}$ statistic was used to quantify the inconsistency between study estimates, and chi-square tests were used to formally test for heterogeneity. Publication/selection bias was investigated by checking for asymmetry in funnel plots. ${ }^{36}$

Where appropriate, random-effect models were used to calculate pooled estimates. ${ }^{35}$ Study-specific weights in the randomeffects model were calculated and scaled to percentages. The analysis was repeated in European and non-European studies, in studies in which fasting samples were taken, in studies in which the cases and controls were closely age matched (to within 3 years), and in studies in which greater than $50 \%$ of the cases had CRVO or BRVOs. The analysis was also repeated, broadly grouping studies by control source (details in Tables 1 and 2).

Publication bias/funnel plot asymmetry was formally tested using Begg's ${ }^{37}$ and Egger's test. ${ }^{38}$ A further sensitivity analysis was conducted using the Trim and Fill method to calculate pooled estimates after adjustment for suspected publication bias/funnel plot asymmetry. ${ }^{39}$ Finally, meta-regression techniques were used to investigate the association between the study characteristics and the observed estimates. All statistical analyses were performed using STATA 9.0 (Stata Corporation, College Station, TX).

\section{Results}

\section{Total Homocysteine}

By using the above search criteria, we found 47 articles for tHcy and RVO. On individual examination of each of these, 36 fitted the inclusion criteria for tHcy. ${ }^{10-12,17-24,27,28,30,32,40-60}$ The remaining 11 articles were meta-analyses, ${ }^{7,16}$ review articles, ${ }^{61}$ commentaries/ letters, ${ }^{62,63}$ case reports, ${ }^{64-69}$ or series. On closer examination, 2 articles were duplicate publications of the same dataset, ${ }^{48,57}$ whereas a further 9 articles did not present the data in a suitable format that could be used for meta-analysis, ${ }^{41,42,46,47,49-51,55,56}$ for example, presenting the tHcy data as percentage of the population with elevated levels ${ }^{41,42,50}$ or not reporting tHcy concentrations or variance in a control groups. ${ }^{47}$

Original data were available from only a limited number of studies $(\mathrm{n}=7) .{ }^{10,27,40,44,45,59,60}$ Thus, the patient-level data were used only for sensitivity analyses.

For the meta-analysis of tHcy we used 25 case-control studies, and the characteristics of these are summarized in Tables 1 and 2. A total of 1533 RVO cases and 1708 control subjects were included.

The forest plot for tHcy and RVO is shown in Figure 1. There was evidence of a greater mean tHcy in the cases compared with the controls in the majority of studies. Overall, the mean tHcy in the cases was $2.8 \mu \mathrm{mol} / \mathrm{L}$ (95\% CI, 1.8-3.7) greater than in the controls, but there was strong evidence of between-study heterogeneity $\left(P<0.001, \mathrm{I}^{2}=93 \%\right)$, suggesting the need for cautious interpretation.

Heterogeneity persisted despite reanalysis in the following subsets of studies: (a) European studies (European $\mathrm{n}=14, P<0.001$, $\mathrm{I}^{2}=90 \%$ ); (b) non-European studies (non-European studies $=11$, $P<0.001, \mathrm{I}^{2}=91 \%$ ); (c) studies with similar cases and control ages (number of studies $=18, P<0.001, \mathrm{I}^{2}=94 \%$ ); (d) studies in which both case and control groups contained more than 35 participants (number of studies $=19, P<0.001, \mathrm{I}^{2}=93 \%$ ); (e) studies in which no approximations were used to impute means or standard errors (number of studies $=20, P<0.001, \mathrm{I}^{2}=92 \%$ ); (f) studies for which we had individual patient data (number of studies $\left.=7, P<0.001, \mathrm{I}^{2}=85 \%\right)$; $(\mathrm{g})$ studies using only fasting samples (number of studies $=18, P<0.001, \mathrm{I}^{2}=93 \%$ ); (h) studies with more than $50 \%$ CRVO cases (number of studies $=17$, $\left.P<0.001, \mathrm{I}^{2}=93 \%\right)$ and studies with less than $50 \%$ CRVO cases (number of studies $=7, P<0.001, \mathrm{I}^{2}=90 \%$ ). A further analysis by type of controls was performed on 3 groups of studies (Table 
Table 1. Characteristics of Studies Examining Plasma Homocysteine and Retinal Vein Occlusion Used in Meta-analysis: Cases

\begin{tabular}{|c|c|c|c|c|c|c|c|c|}
\hline \multirow[b]{2}{*}{$\begin{array}{l}\text { First Author } \\
\text { (Reference) }\end{array}$} & \multirow[b]{2}{*}{$\begin{array}{l}\text { Publication } \\
\text { Year }\end{array}$} & \multirow[b]{2}{*}{$\begin{array}{l}\text { Country of } \\
\text { Origin }\end{array}$} & \multirow[b]{2}{*}{ Fasting } & \multicolumn{5}{|c|}{ Cases } \\
\hline & & & & $n$ & $B R V O$ & $\mathrm{CRVO}$ & $\begin{array}{c}\text { Age, yr } \\
\text { Mean (SD) }\end{array}$ & $\begin{array}{c}\text { Ascertainment } \\
\text { (Time Since Diagnosis) }\end{array}$ \\
\hline Cahill ${ }^{45}$ & 2000 & Ireland & yes & 61 & 21 & 40 & $69(-)$ & Hospital records $(3-12 \mathrm{mos})$ \\
\hline Vine $^{58}$ & 2000 & US & no & 74 & 0 & 74 & 70 (range 40-88) & Hospital records ( $<10 \mathrm{yrs})$ \\
\hline Larsson $^{52 a}$ & 2000 & Sweden & no & $\begin{array}{l}37 \\
79\end{array}$ & 0 & $\begin{array}{l}37 \\
79\end{array}$ & $\begin{array}{l}41 \text { (range } 20-49) \\
70 \text { (range 50-91) }\end{array}$ & Hospital records $(<4$ yrs $)$ \\
\hline Pianka ${ }^{54}$ & 2000 & Israel & no & 21 & 0 & 21 & $59(12)$ & Consecutive patients \\
\hline Martin $^{53}$ & 2000 & UK & yes & 60 & 24 & 36 & $66(13)$ & Consecutive patients \\
\hline Marcucci $^{27}$ & 2001 & Italy & yes & 100 & 0 & 100 & Median 59 (range 18-77) & Consecutive patients ( $<2$ yrs) \\
\hline Boyd $^{30}$ & 2001 & UK & no & 63 & 0 & 63 & $60(16)$ & Consecutive patients ( $<3 \mathrm{mos})$ \\
\hline Brown $^{44}$ & 2002 & US & yes & $20^{\mathrm{b}}$ & 15 & 3 & $69(11)$ & Hospital records $(<6 \mathrm{mos})$ \\
\hline Weger $^{59}$ & 2002 & Austria & yes & 84 & 84 & 0 & $68(11)$ & Consecutive patients \\
\hline Weger $^{60}$ & 2002 & Austria & yes & 78 & 0 & 78 & $69(11)$ & Consecutive patients \\
\hline El-Asrar ${ }^{40}$ & 2002 & Saudi Arabia & no & 48 & 12 & 36 & $45(11)$ & $\begin{array}{l}\text { Consecutive patients ("recently } \\
\text { diagnosed") }\end{array}$ \\
\hline Blondel $^{43}$ & 2002 & France & - & 101 & 16 & 85 & $54(14)$ & Consecutive patients \\
\hline Marcucci $^{28}$ & 2003 & Italy & yes & 55 & 29 & 26 & Median 57 (range 18-82) & Consecutive patients ( $<2$ yrs $)$ \\
\hline Parodi $^{32}$ & 2003 & Italy & yes & 31 & 0 & 31 & $45(-)$ & Consecutive patients $(<1 \mathrm{wk})$ \\
\hline Yildirim $^{17}$ & 2004 & Turkey & yes & $33^{\mathrm{b}}$ & 20 & 9 & 61 (range 37-79) & Consecutive patients $(<6 \mathrm{mos})$ \\
\hline Yaghoubi $^{18}$ & 2004 & Iran & yes & $25^{\mathrm{b}}$ & 10 & 14 & $61(12)$ & Hospital records \\
\hline Atchaneeyasakul ${ }^{11}$ & 2005 & Thailand & yes & $32^{\mathrm{b}}$ & 15 & 11 & $54(13)$ & Consecutive patients $(<2 \mathrm{wks})$ \\
\hline Terrazzi ${ }^{19}$ & 2005 & Italy & yes & 69 & - & - & $64(15)$ & Consecutive patients $(<1 \mathrm{wk})$ \\
\hline McGimpse ${ }^{10}$ & 2005 & UK & no & 100 & 43 & 57 & $68(14)$ & Hospital records \\
\hline Lattanzio ${ }^{20}$ & 2006 & Italy & no & 58 & 0 & 58 & $40(10)$ & Consecutive patients $(<1 \mathrm{yr})$ \\
\hline $\mathrm{Gao}^{23}$ & 2006 & China & yes & 64 & 0 & 64 & $60(4)$ & Consecutive patients $(<3 \mathrm{mos})$ \\
\hline Gumus $^{24}$ & 2006 & Turkey & yes & 82 & 56 & 26 & $58(9)$ & $\begin{array}{l}\text { Consecutive patients/hospital } \\
\text { records }\end{array}$ \\
\hline Pinna $^{12}$ & 2006 & Italy & yes & 75 & 42 & 33 & $64(15)$ & Consecutive patients \\
\hline Narayanasamy $^{21}$ & 2007 & India & yes & 29 & 0 & 29 & $30(6)$ & Consecutive patients \\
\hline Moghimi $^{22}$ & 2007 & Iran & yes & 54 & 0 & 54 & $60(13)$ & $(<1 \mathrm{mo})$ \\
\hline
\end{tabular}

$\mathrm{BRVO}=$ branch retinal vein occlusion; $\mathrm{CRVO}=$ central retinal vein occlusion; $\mathrm{SD}=$ standard deviation.

aData presented in 2 age groups: $<50$ yrs and $>50$ yrs.

bIncludes others (e.g., hemi-retinal, hemispheric, macular).

2): Controls who were hospital staff or healthy volunteers and people with cardiovascular disease were excluded (number of studies $=9, P<0.001, \mathrm{I}^{2}=93 \%$ ): studies with controls who were patients attending hospital (usually ophthalmology outpatients clinics but without known retinal disease) (number of studies $=9$, $P=0.36, \mathrm{I}^{2}=8 \%$ ) and studies in which the control group was unclear (number of studies $=7, P<0.001, \mathrm{I}^{2}=89 \%$ ). The estimates from studies in which control patients had mostly other diseases were fairly homogenous. ${ }^{18,10,22,24,30,45,58,59,60}$ The mean tHcy was $1.83 \mu \mathrm{mol} / \mathrm{L}(95 \% \mathrm{CI}, 1.3-2.3 ; P<0.001)$ greater in cases than in the controls in this group.

The funnel plot in Figure 2 did not conform to the expected funnel shape. There is some evidence that the larger studies observed smaller differences in mean between the cases and controls than the smaller studies. The shape of the observed funnel plot could have arisen from the non-publication of small studies, which observed no difference in mean, or a slight reduction in mean, in the cases compared with the controls, although other explanations are possible. Formal tests revealed evidence of funnel plot asymmetry perhaps due to publication bias (Begg's test $P=0.012$, Egger's test $P=0.08)$. However, the pooled estimate was unaltered (overall difference in mean $=2.8 \mu \mathrm{mol} / \mathrm{L}$ ) after conducting the Trim and Fill method to attempt to adjust for funnel plot asymmetry/publication bias, suggesting that any such bias had little effect on the overall findings.

Finally, meta-regression techniques demonstrated little evidence of an association $(P=0.39)$ between the difference in mean
tHcy between cases and controls and the difference in mean ages between the cases and controls.

\section{Methylenetetrahydrofolate Reductase}

We found 25 published journal articles on MTHFR and RVO, of which 18 fitted the inclusion criteria. ${ }^{10,19,27,28,30,32,35,41,47,49,52,59,60,70-74}$ Exclusions were 3 case reports/series, ${ }^{68,75,76} 2$ meta-analyses, ${ }^{7,16} 1$ review, ${ }^{77}$ and 1 article reporting duplicate data. ${ }^{48}$

A total of 1082 RVO cases and 4706 controls were included in the analysis. The Forest plot for thermolabile MTHFR polymorphism and RVO is shown in Figure 3. Overall there was no evidence of any association between MTHFR and RVO (OR = $1.20 ; 95 \% \mathrm{CI}, 0.84-1.71)$, but there was marked heterogeneity $\left(P=0.004, \mathrm{I}^{2}=53 \%\right)$ between studies.

For MTHFR, the funnel plots demonstrate the expected pattern without significant departure from symmetry (Fig 4). There was also no evidence of publication bias after formal testing (Begg's test $P=0.43$, Egger's test $=0.30$ ).

\section{Discussion}

We performed a meta-analysis to determine the association among tHcy, MTHFR C677T genotype, and RVO risk. We found a statistically significant association between 
Table 2. Characteristics of Studies Examining Plasma Homocysteine and Retinal Vein Occlusion Used in Meta-analysis: Controls

\begin{tabular}{|c|c|c|c|c|c|c|}
\hline \multirow[b]{2}{*}{$\begin{array}{l}\text { First Author } \\
\text { (Reference) }\end{array}$} & \multirow[b]{2}{*}{$\begin{array}{l}\text { Publication } \\
\text { Year }\end{array}$} & \multirow[b]{2}{*}{$\begin{array}{l}\text { Country of } \\
\text { Origin }\end{array}$} & \multirow[b]{2}{*}{ Fasting } & \multicolumn{3}{|r|}{ Controls } \\
\hline & & & & $n$ & $\begin{array}{l}\text { Age, yr } \\
\text { Mean (SD) }\end{array}$ & $\begin{array}{c}\text { Source } \\
\text { (Matching Criteria) }\end{array}$ \\
\hline Cahill ${ }^{45}$ & 2000 & Ireland & yes & 87 & $70(-)$ & Hospital patients, primarily cataract extraction (age $)^{\mathrm{d}}$ \\
\hline Vine $e^{58}$ & 2000 & US & no & 74 & 65 (range 37-90) & Hospital patients with non-retinal vascular diagnosis ${ }^{\mathrm{d}}$ \\
\hline Larsson $^{52 a}$ & 2000 & Sweden & no & $\begin{array}{l}65 \\
88\end{array}$ & $\begin{array}{l}41 \text { (range } 20-49) \\
70 \text { (range } 50-88 \text { ) }\end{array}$ & Unknown, "randomly selected" (age) ${ }^{\mathrm{e}}$ \\
\hline Pianka ${ }^{54}$ & 2000 & Israel & no & 81 & $66(18)$ & Unknown, "healthy adults"c \\
\hline Martin $^{53}$ & 2000 & UK & yes & 85 & $52(15)$ & $\begin{array}{l}\text { Laboratory staff/hospital patients, no cardiovascular } \\
\text { disease }^{c}\end{array}$ \\
\hline Marcucci $^{27}$ & 2001 & Italy & yes & 100 & Median 56 (range 18-84) & Friends/partners, no cardiovascular disease $(\text { age, sex })^{c}$ \\
\hline Boyd $^{30}$ & 2001 & UK & no & 63 & $61(16)$ & Clinic patients ${ }^{\mathrm{d}}$ \\
\hline Brown $^{44}$ & 2002 & US & yes & 20 & $70(7)$ & Unknown, "normal subjects" with no diabetes ${ }^{\text {be }}$ \\
\hline Weger $^{59}$ & 2002 & Austria & yes & 84 & $68(11)$ & $\begin{array}{l}\text { Hospital patients, no anterior ischemic optic } \\
\text { neuropathy or vasculitis }(\text { age, sex })^{\mathrm{d}}\end{array}$ \\
\hline Weger $^{60}$ & 2002 & Austria & yes & 78 & $69(11)$ & $\begin{array}{l}\text { Hospital patients, no anterior ischemic optic } \\
\text { neuropathy or vasculitis (age, sex })^{\mathrm{d}}\end{array}$ \\
\hline El-Asrar ${ }^{40}$ & 2002 & Saudi Arabia & no & 59 & $46(12)$ & Healthy blood donors $(\text { age, sex })^{c}$ \\
\hline Blondel $^{43}$ & 2002 & France & - & 29 & $51(10)$ & Source not given, (age $)^{\mathrm{e}}$ \\
\hline Marcucci $^{28}$ & 2003 & Italy & yes & 61 & Median 56 (range 20-80) & $\begin{array}{l}\text { Friends/partners, no cardiovascular disease or venous } \\
\text { thromboembolism }(\text { age, sex })^{c}\end{array}$ \\
\hline Parodi ${ }^{32}$ & 2003 & Italy & yes & 31 & $44(-)$ & Unknown, "volunteers" (age, sex) \\
\hline Yildirim $^{17}$ & 2004 & Turkey & yes & 25 & 58 (range 47-72) & Unknown $(\text { age, sex })^{\mathrm{e}}$ \\
\hline Yaghoubi $^{18}$ & 2004 & Iran & yes & 24 & $63(14)$ & $\begin{array}{l}\text { Clinic patients, no glaucoma, uveitis or intraocular } \\
\text { trauma }^{\mathrm{d}}\end{array}$ \\
\hline Atchaneeyasakul ${ }^{11}$ & 2005 & Thailand & yes & 88 & $54(13)$ & Unknown, "volunteers" (age, sex) \\
\hline Terrazzi $^{19}$ & 2005 & Italy & yes & 50 & $58(12)$ & Unknown, "volunteers" (age) ${ }^{\mathrm{e}}$ \\
\hline McGimpse $^{10}$ & 2005 & UK & no & 91 & $68(14)$ & $\begin{array}{l}\text { Clinic patients (primarily cataract surgery)/friends/ } \\
\text { relatives }(\text { age, sex })^{\mathrm{d}}\end{array}$ \\
\hline Lattanzio ${ }^{20}$ & 2006 & Italy & no & 103 & $40(13)$ & Hospital staff ${ }^{c}$ \\
\hline $\mathrm{GaO}^{23}$ & 2006 & China & yes & 64 & $60(4)$ & $\begin{array}{l}\text { Volunteers undergoing routine physical examination } \\
\text { (age, sex, hypertension, smoking, drinking) }{ }^{c}\end{array}$ \\
\hline Gumus $^{24}$ & 2006 & Turkey & yes & 78 & $57(10)$ & $\begin{array}{l}\text { Clinic patients with refractive errors, presbyopia, or } \\
\text { cataract }(\text { age, sex })^{\mathrm{d}}\end{array}$ \\
\hline Pinna $^{12}$ & 2006 & Italy & yes & 72 & $64(8)$ & Friends/partners/hospital staff ${ }^{c}$ \\
\hline Narayanasamy ${ }^{21}$ & 2007 & India & yes & 57 & $27(5)$ & Hospital staff/students (age, sex $)^{c}$ \\
\hline Moghimi $^{22}$ & 2007 & Iran & yes & 51 & $63(9)$ & $\begin{array}{l}\text { Clinic patients, no retinal disease (age, sex, } \\
\text { hypertension, diabetes, smoking) }\end{array}$ \\
\hline \multicolumn{7}{|c|}{$\begin{array}{l}\text { SD }=\text { standard deviation. } \\
\text { aD Data presented in } 2 \text { age groups: }<50 \text { yrs and }>50 \text { yrs. } \\
\text { bStudy included } 2 \text { controls; group information represents control group used in meta-analysis. } \\
\text { cClassified as healthy controls, volunteers, or excluding cardiovascular disease. } \\
\text { d Studies using mainly controls with other diseases and not excluding cardiovascular risk factors. } \\
\text { eStudies in which the control group was unclear. }\end{array}$} \\
\hline
\end{tabular}

increased tHcy serum levels and RVO risk. We did not find any association between MTHFR C677T genotype and RVO risk. Although our combined estimates are similar to 2 previous meta-analyses, the inclusion of 15 additional studies have highlighted marked heterogeneity in the associations between studies from unidentified sources. Also, in contrast with these previous meta-analyses, funnel plots indicated that the association between tHcy and RVO seems less marked in larger studies, perhaps because of publication bias. ${ }^{7,16}$

\section{Study Heterogeneity}

One of the strengths of this analysis was the exploration of the heterogeneity of the association between tHcy and RVO. However, our attempts to identify homogeneous subsets were largely unsuccessful, except for a subgroup of studies in which the control group comprised hospital patients, making any firm conclusions difficult.

We attempted to reduce heterogeneity by considering the geographic origin of studies, classifying them as European and non-European, because a previous meta-analysis of MTHFR C677T polymorphism and coronary heart disease risk showed that heterogeneity disappeared when studies were stratified by geographic region. ${ }^{78}$ However, this was not observed in the current study.

Homocysteine concentrations are greater in the non-fasting than fasting state, and therefore it is recommended that blood samples are acquired after a period of fasting. ${ }^{13}$ This is not always possible when opportunistic sampling methods are used and only two thirds of the studies included in the metaanalysis had used fasting glucose samples. However, exclusion 


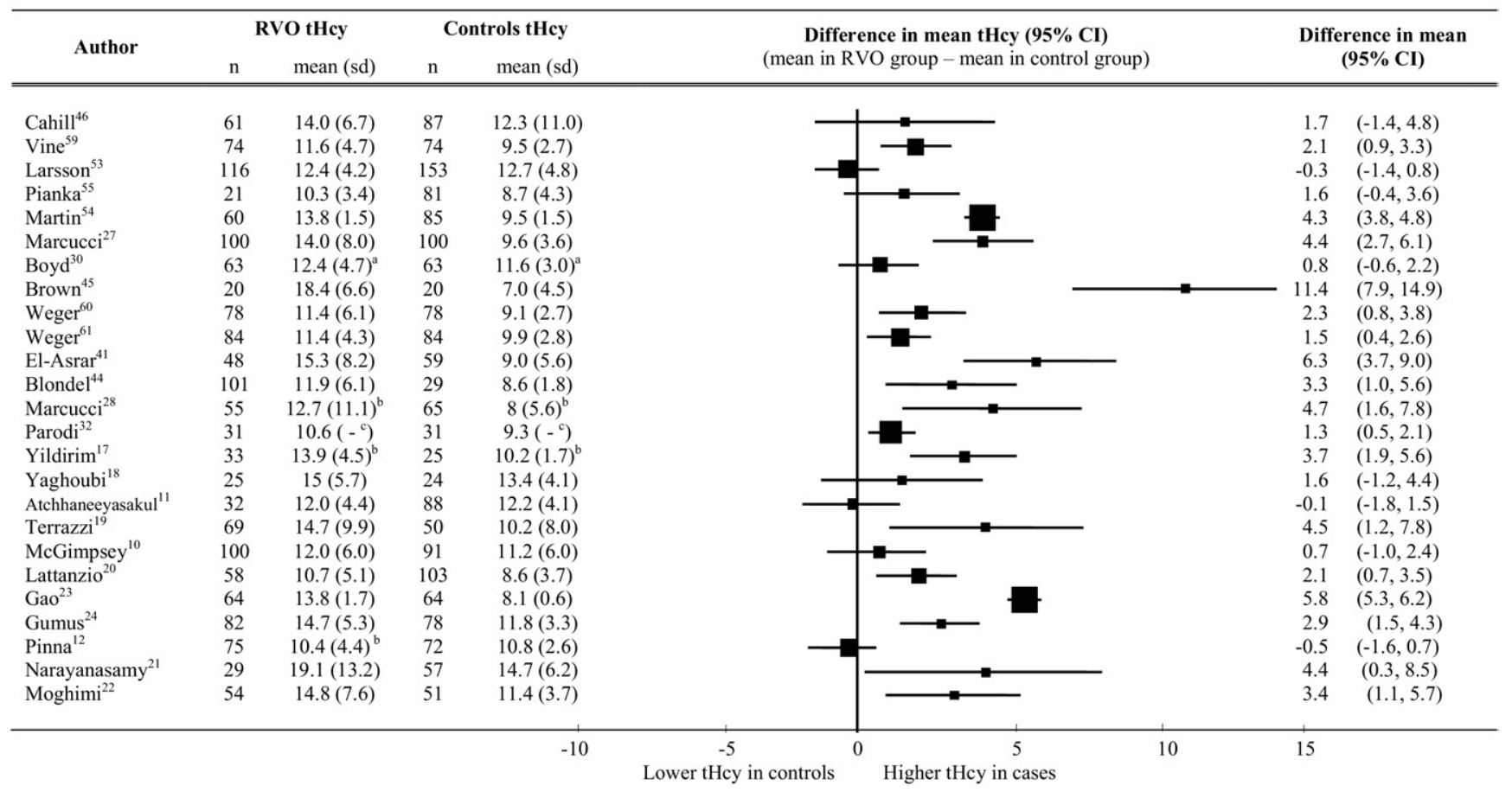

*Test for heterogeneity $\chi^{2}=327.77, \mathrm{df}=24, \mathrm{P}<0.001 ; \mathrm{I}^{2}(95 \% \mathrm{CI})=93 \%(90 \%, 94 \%)$.

${ }^{a}$ Mean and standard deviation (sd) estimated from the median and the interquartile range. ${ }^{31}$

${ }^{\mathrm{b}}$ Mean and standard deviation (sd) estimated from the median and range. ${ }^{29}$

${ }^{\mathrm{c}}$ Standard deviation estimates not available within groups, standard error of difference in means estimated from P-value of t-test. ${ }^{33}$

Confidence interval (CI).

Figure 1. Forest plot of studies of $\mathrm{tHcy}(\mu \mathrm{mol} / \mathrm{L})$ and $\mathrm{RVO}$, ordered by date of publication. $\mathrm{CI}=$ confidence interval; $\mathrm{RVO}=$ retinal vein occlusion; $\mathrm{SD}=$ standard deviation; $\mathrm{tHcy}=$ total homocysteine.

of studies that did not use fasting samples did not reduce heterogeneity.

Summary statistics published by the authors were used for the meta-analysis because patient-level data were not available to us in the majority of the studies. However, when we carried out a subgroup analysis that was limited to those studies for which we had patient-level data, the esti-

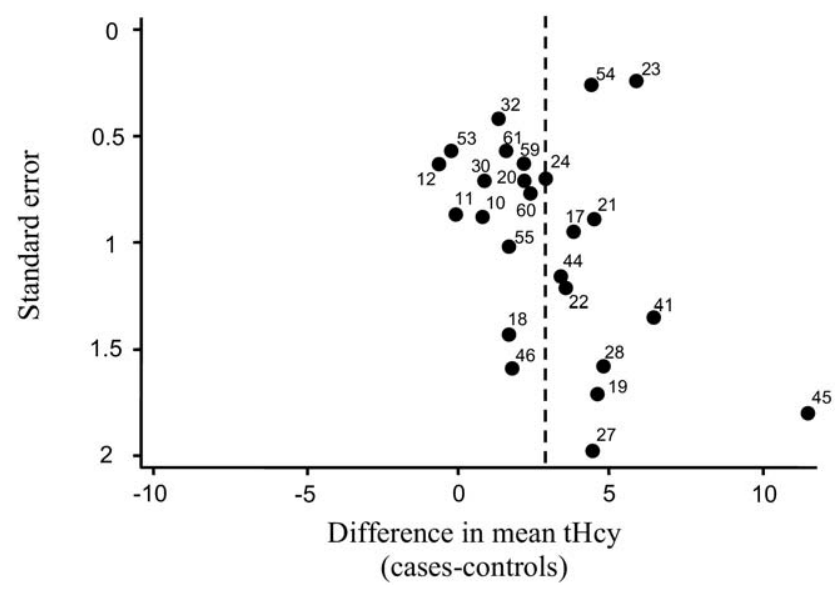

Figure 2. Funnel plot of studies of tHcy and RVO, labeled by reference number. Dashed line denotes combined mean. tHcy $=$ total homocysteine. mates of risk increase were similar, and heterogeneity was not reduced.

A further possible reason for heterogeneity in this meta-analysis is that we included both branch and central RVO, because in most of the studies a distinction was not made between these 2 disease groups. It has been suggested that, although central RVO is associated with cardiovascular risk factors, branch RVO may be more influenced by local factors such as atherosclerotic retinal arteries compressing retinal veins at arteriovenous crossings, and therefore the cause of these conditions may be different. ${ }^{45} \mathrm{We}$ did attempt to address this and repeated the analysis in studies in which more than $50 \%$ of cases had CRVO and in studies in which more than $50 \%$ of cases had BRVO, but in both subgroups there was a high level of heterogeneity and the difference in tHcy between cases and controls in these 2 groups was similar, indicating that the role of tHcy is unlikely to differ in the cause of these 2 conditions.

A crucial consideration in case-control studies is the selection of the control group. An ideal control group in a case-control study will be as similar as possible to the cases, except that they would not have the disease being investigated. We found wide variability in the source of control group between the studies that could have lead to the observed heterogeneity of our results. The controls in 
McGimpsey et al • Homocysteine, MTHFR, and Retinal Vein Occlusion: A Meta-analysis

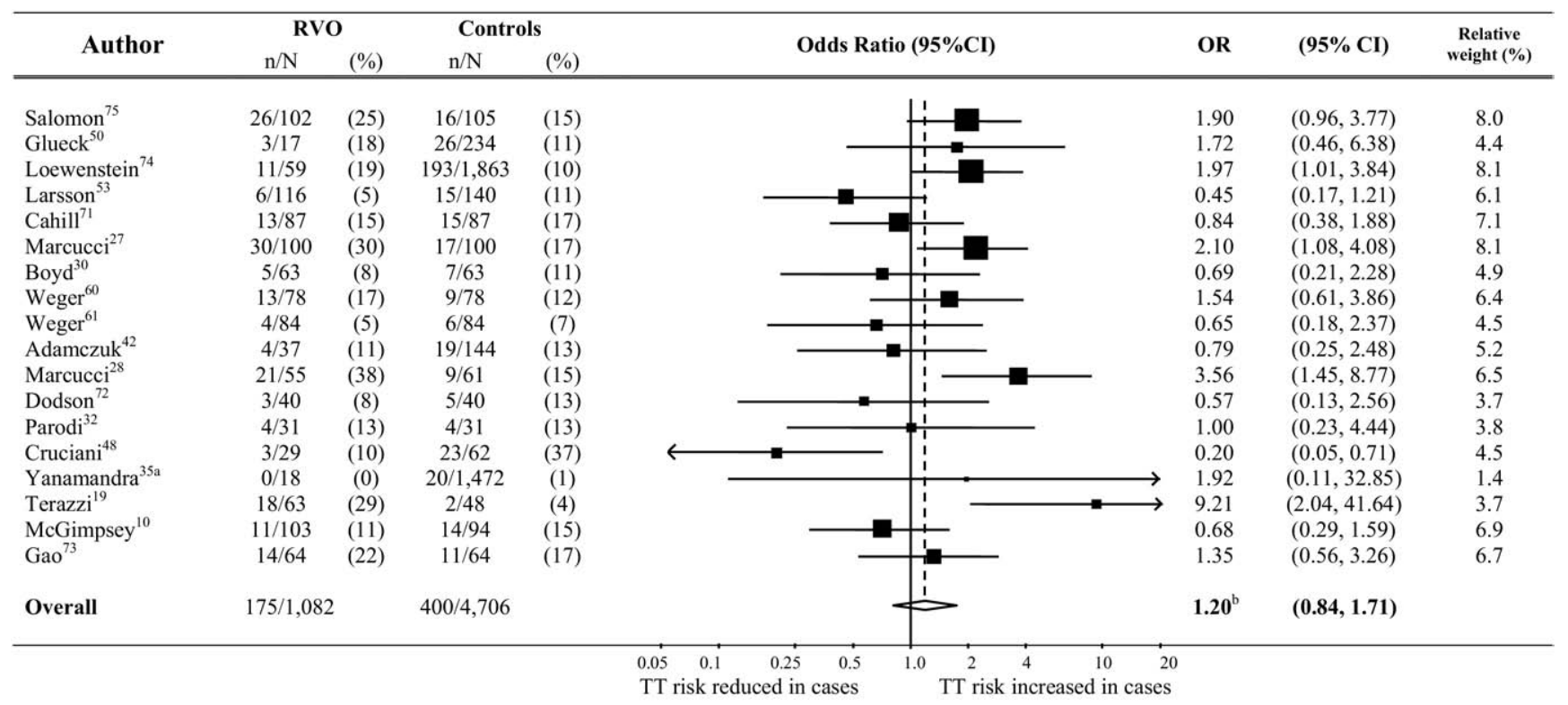

$\mathrm{n}$, number with MTHFR TT allele; $\mathrm{N}$, total number in RVO and control groups.

${ }^{\text {a }}$ Correction added to calculate odds ratio (OR) and $95 \%$ confidence interval $(\mathrm{CI})^{36}$

${ }^{\mathrm{b}}$ Test for heterogeneity $\chi^{2}=36.5, \mathrm{df}=17, \mathrm{P}=0.004 ; \mathrm{I}^{2}(95 \% \mathrm{CI})=53 \%(20 \%, 73 \%)$.

Figure 3. Forest plot of studies investigating the association between thermolabile MTHFR genotype (comparing TT heterozygotes with heterozygotes $[\mathrm{CT}]$ and wild-type homozygotes [CC]) and RVO using the random effects model, ordered by date of publication. $\mathrm{CI}=$ confidence interval; OR $=$ odds ratio; $\mathrm{RVO}=$ retinal vein occlusion.

the studies usually comprised hospital staff, healthy volunteers, or patients attending hospital (usually ophthalmology outpatient clinics, but without known retinal disease), whereas in some studies the source of controls was not clearly stated. There are strengths and weaknesses in the use of either hospital- or community-based controls. tHcy has been shown to be elevated in several diseases, including cardiovascular disease, and the use of healthy controls or volunteers (e.g., excluding those with cardiovascular disease) may enhance mild associations with a phenomenon referred to as the "healthy participant effect." Therefore, the use of hospitalbased controls may be more appropriate here because these patients' characteristics may be closer to that of the case group.

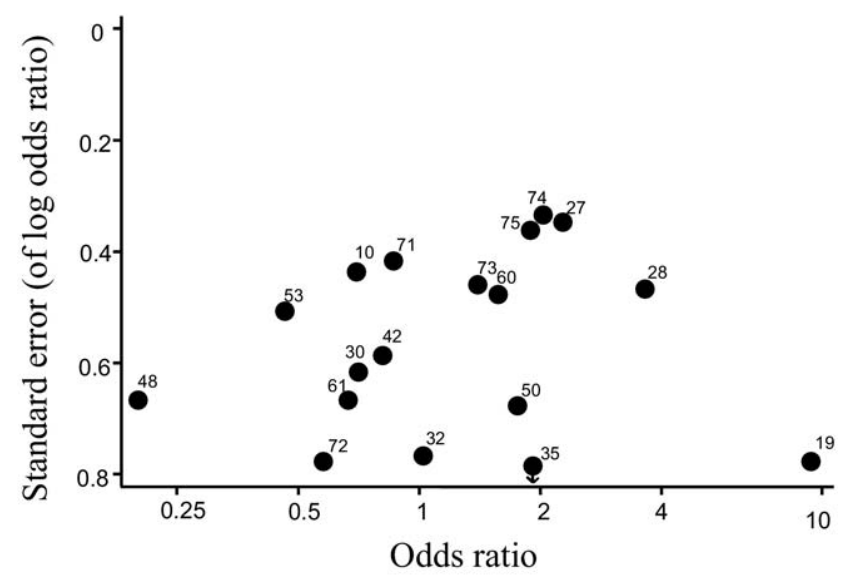

Figure 4. Funnel plot of studies investigating the association between thermolabile MTHFR genotype (comparing TT genotype with heterozygous CT and homozygous CC genotypes) and RVO.
An observed greater tHcy concentration in RVO cases than in hospital-based controls is then likely to be due to RVO rather than the presence of other conditions. We observed less heterogeneity in studies that recruited their control patients from those attending a hospital. However, even within this group of studies there was variability in how controls were selected. Although this subgroup did demonstrate a significant association between tHcy and RVO, the difference between cases and controls was lower than that observed within the overall metaanalysis. Thus, we recommend that our results be interpreted cautiously, because many subsets of studies were investigated. Nonetheless, it is reassuring that the overall findings were similar within these studies.

The difference in mean ages between the cases and controls could account for some of the between-study variability because there is evidence showing that tHcy increases with age. ${ }^{13}$ For example, in one study ${ }^{53}$ cases were on average 14 years older than their controls. However, there was no evidence of more homogenous findings in the group of studies with an age difference between cases and controls of less than 3 years. Furthermore, meta-regression showed no evidence of a correlation between the difference in mean tHcy between cases and controls and the difference in mean age between cases and controls. These analyses, although rather crude, suggest that a difference in age between cases and controls does not account for much of the variability in the study estimates.

\section{Limitations of the Meta-analysis}

The case-control study design means that the assessment of thcy in patients at varying time intervals after the 
occlusive vascular event is methodologically weak. The vascular occlusive event itself could increase the tHcy concentration, and this type of reverse causality is supported by studies of tHcy and coronary heart disease in which evidence from longitudinal cohorts demonstrate weaker associations than those found in the case-control scenario. ${ }^{8}$

We were also unable assess the contribution of confounding factors to the observed results. tHcy is elevated in several conditions, including cardiovascular disease, ${ }^{8,9}$ and is positively associated with renal function, ${ }^{13}$ There are a number of dietary determinants of tHcy, including Bvitamin status ${ }^{13}$ and fruit and vegetable intake, ${ }^{79,80}$ whereas certain drugs and cigarette smoking can interfere with folate/tHcy metabolism. ${ }^{13}$ Imbalances in these parameters between cases and controls have the potential to influence the results.

For example, we were unable to account for folate status in this meta-analysis because it was only examined in a small number of studies. It is therefore a possibility that differences in folate intake between studies explain the observed heterogeneity.

\section{Effect of Publication Bias}

For obvious reasons it is recognized that studies yielding significant results are more likely to be published leading to publication bias. The funnel plot (Fig 2) indicated that larger studies observed smaller differences in mean between the cases and controls than smaller studies. This observation is consistent with publication bias because studies with smaller sample sizes that may have been conducted and that did not detect a difference between cases and controls were not published. If this is the case, then our combined estimate would exaggerate the true difference in mean tHcy between the cases and controls. Alternatively, it is possible that the funnel plot shape could have arisen because the larger studies differed from the smaller studies with respect to other study characteristics, such as quality. By ignoring the funnel plot and significant heterogeneity, it would be easy to conclude that an association exists between tHcy and RVO. However, the marked heterogeneity in the studies, except for the subgroup of studies that used hospital patients as controls, and the evidence of publication bias are strong reasons for questioning the finding that tHcy and RVO are related.

\section{Thermolabile Methylenetetrahydrofolate Reductase and Retinal Vein Occlusion Risk}

Because of the weaknesses in the case-control approach outlined above (residual confounding and reverse causality), it has been proposed that a more robust method for detecting association would be to examine the relationship between the genetic variant MTHFR C677T and elevated tHcy concentrations, ${ }^{14,15}$ because this will not be subject to reverse causation or the confounding that exists in observational studies of disease risk in relation to directly measured tHcy concentrations. ${ }^{78}$ This approach follows the principle of Mendelian randomization. ${ }^{81}$ By examining the associa- tion between MTHFR C677T genotype and RVO risk, we found no association between homozygosity for the TT genotype and RVO risk. Heterogeneity between studies was high, but there was no indication of publication bias.

There are several possible explanations for this lack of association between MTHFR and RVO risk, other than a true lack of association. Differences in tHcy concentration by MTHFR C677T genotype have been shown to be greater at lower levels of folate intake and status, and are reduced after folate supplementation. ${ }^{26} \mathrm{We}$ did not have information on folate status in the majority of studies and thus were unable to account for folate status in our analysis.

Second, with 1082 cases and 4706 controls, this is still a modestly sized meta-analysis in terms of genetic polymorphisms, and the power to detect a small increase in risk may be limited.

Overall, the findings from our meta-analysis on the lack of an association between MTHFR C677T genotype and RVO risk are consistent with the possibility that weaknesses in the study design may have contributed to the observation of a positive association between tHcy and RVO in the individual studies and the overall metaanalysis.

Despite the inclusion of 15 additional case-control studies after initial meta-analyses, ${ }^{7,16}$ we were still unable to draw firm conclusions on the relationship among tHcy, MTHFR, and RVO. The majority of studies published have tended to conclude that an association between tHcy and RVO exists, and our meta-analysis supports this view through the finding of a significantly increased pooled estimate, suggesting that reduction of tHcy with folate supplementation may reduce RVO risk. However, the presence of marked heterogeneity and clear evidence of publication bias makes direct comparison and pooling of the results unreliable. The pooled increase in risk due to tHcy is also not in accord with the absence of an association between RVO and MTHFR TT genotype. Therefore, the association between tHcy and RVO remains tentative and requires high-quality, well-designed epidemiologic studies, preferably of cohort design, before firm conclusions on the putative role of elevated tHcy and MTHFR status on RVO occlusion can be made.

In conclusion, there is evidence to suggest an association between tHcy and RVO. Because of the presence of heterogeneity and publication bias, no recommendation can be made with regard to routine investigation and treatment of elevated tHcy in the setting of RVO (rating CIII). There is no evidence to suggest an association between MTHFR C677T genotype and RVO. There was heterogeneity between groups but no evidence of publication bias. There is no evidence to suggest routine testing of MTHFR C677T genotype in clinical practice (rating CII).

\section{References}

1. David R, Zangwill L, Badarna M, Yassur Y. Epidemiology of retinal vein occlusion and its association with glaucoma and increased intraocular pressure. Ophthalmologica 1988;197: 69-74. 
2. Klein R, Wang Q, Klein BE, et al. The relationship of agerelated maculopathy, cataract, and glaucoma to visual acuity. Invest Ophthalmol Vis Sci 1995;36:182-91.

3. Martin SC, Butcher A, Martin N, et al. Cardiovascular risk assessment in patients with retinal vein occlusion. Br J Ophthalmol 2002;86:774-6.

4. Tsaloumas MD, Kirwan J, Vinall H, et al. Nine year follow-up study of morbidity and mortality in retinal vein occlusion. Eye 2000;14: $821-7$.

5. Hayreh SS, Zimmerman B, McCarthy MJ, Podhajsky P. Systemic diseases associated with various types of retinal vein occlusion. Am J Ophthalmol 2001;131:61-77.

6. Deramo VA, Cox TA, Syed AB, et al. Vision-related quality of life in people with central retinal vein occlusion using the 25-item National Eye Institute Visual Function Questionnaire. Arch Ophthalmol 2003;121:1297-302.

7. Cahill MT, Stinnett SS, Fekrat S. Meta-analysis of plasma homocysteine, serum folate, serum vitamin B(12), and thermolabile MTHFR genotype as risk factors for retinal vascular occlusive disease. Am J Ophthalmol 2003;136:1136-50.

8. Clarke R. Commentary: an updated review of the published studies of homocysteine and cardiovascular disease. Int $\mathbf{J}$ Epidemiol 2002;31:70-1.

9. Wald DS, Wald NJ, Morris JK, Law M. Folic acid, homocysteine, and cardiovascular disease: judging causality in the face of inconclusive trial evidence. BMJ 2006;333:1114-7.

10. McGimpsey SJ, Woodside JV, Bamford L, et al. Retinal vein occlusion, homocysteine, and methylene tetrahydrofolate reductase genotype. Invest Ophthalmol Vis Sci 2005; 46:4712-6.

11. Atchaneeyasakul LO, Trinavarat A, Bumrungsuk P, Wongsawad W. Anticardiolipin IgG antibody and homocysteine as possible risk factors for retinal vascular occlusive disease in Thai patients. Jpn J Ophthalmol 2005;49:211-5.

12. Pinna A, Carru C, Zinellu A, et al. Plasma homocysteine and cysteine levels in retinal vein occlusion. Invest Ophthalmol Vis Sci 2006;47:4067-71.

13. Refsum H, Smith AD, Ueland PM, et al. Facts and recommendations about total homocysteine determinations: an expert opinion. Clin Chem 2004;50:3-32.

14. Harmon DL, Woodside JV, Yarnell JW, et al. The common 'thermolabile' variant of methylene tetrahydrofolate reductase is a major determinant of mild hyperhomocysteinaemia. QJM 1996;89:571-7.

15. Jacques PF, Bostom AG, Williams RR, et al. Relation between folate status, a common mutation in methylenetetrahydrofolate reductase, and plasma homocysteine concentrations. Circulation 1996;93:7-9.

16. Janssen MC, den Heijer M, Cruysberg JR, et al. Retinal vein occlusion: a form of venous thrombosis or a complication of atherosclerosis? A meta-analysis of thrombophilic factors. Thromb Haemost 2005;93:1021-6.

17. Yildirim C, Yaylali V, Tatlipinar S, et al. Hyperhomocysteinemia: a risk factor for retinal vein occlusion. Ophthalmologica 2004;218:102-6.

18. Yaghoubi GH, Madarshahian F, Mosavi M. Hyperhomocysteinaemia: risk of retinal vascular occlusion. East Mediterr Health J 2004;10:633-9.

19. Terrazzi P, Di Micco P, Quaglia I, et al. Homocysteine, MTHFR C677T gene polymorphism, folic acid and vitamin B 12 in patients with retinal vein occlusion. Thromb $\mathrm{J}$ [serial online] 2005;3:13. Available at: http://www.thrombosisjournal. com/content/3/1/13. Accessed December 17, 2008.

20. Lattanzio R, Sampietro F, Ramoni A, et al. Moderate hyperhomocysteinemia and early-onset central retinal vein occlusion. Retina 2006;26:65-70.
21. Narayanasamy A, Subramaniam B, Karunakaran C, et al. Hyperhomocysteinemia and low methionine stress are risk factors for central retinal venous occlusion in an Indian population. Invest Ophthalmol Vis Sci 2007;48:1441-6.

22. Moghimi S, Najmi Z, Faghihi H, et al. Hyperhomocysteinemia and central retinal vein occlusion in Iranian population. Int Ophthalmol 2008;28:23-8.

23. Gao W, Wang YS, Zhang P, Wang HY. Hyperhomocysteinemia and low plasma folate as risk factors for central retinal vein occlusion: a case-control study in a Chinese population. Graefes Arch Clin Exp Ophthalmol 2006;244: 1246-9.

24. Gumus K, Kadayifcilar S, Eldem B, et al. Is elevated level of soluble endothelial protein $\mathrm{C}$ receptor a new risk factor for retinal vein occlusion? Clin Experiment Ophthalmol 2006;34: 305-11.

25. Woodside JV, Yarnell JW, McMaster D, et al. Effect of B-group vitamins and antioxidant vitamins on hyperhomocysteinemia: a double-blind, randomized, factorial-design, controlled trial. Am J Clin Nutr 1998;67:858-66.

26. Ashfield-Watt PA, Pullin $\mathrm{CH}$, Whiting JM, et al. Methylenetetrahydrofolate reductase $677 \mathrm{C}->\mathrm{T}$ genotype modulates homocysteine responses to a folate-rich diet or a low-dose folic acid supplement: a randomized controlled trial. Am J Clin Nutr 2002;76:180-6.

27. Marcucci R, Bertini L, Giusti B, et al. Thrombophilic risk factors in patients with central retinal vein occlusion. Thromb Haemost 2001;86:772-6.

28. Marcucci R, Giusti B, Betti I, et al. Genetic determinants of fasting and post-methionine hyperhomocysteinemia in patients with retinal vein occlusion. Thromb Res 2003;110: $7-12$.

29. Hozo SP, Djulbegovic B, Hozo I. Estimating the mean and variance from the median, range, and the size of a sample. BMC Med Res Methodol [serial online] 2005;5:13. Available at: http://www.biomedcentral.com/1471-2288/5/13. Accessed December 17, 2008.

30. Boyd S, Owens D, Gin T, et al. Plasma homocysteine, methylene tetrahydrofolate reductase C677T and factor II G20210A polymorphisms, factor VIII, and VWF in central retinal vein occlusion. $\mathrm{Br} \mathrm{J}$ Ophthalmol 2001;85:13135.

31. Higgins JP, Green S, eds. Cochrane Handbook for Systematic Reviews of Interventions. Version 5.0.1(updated September 2008): Section 7.7.3.5 The Cochrane Collaboration 2008. Available at: http://www.cochrane-handbook.org/. Accessed December 17, 2008.

32. Parodi MB, Di Crecchio L. Hyperhomocysteinemia in central retinal vein occlusion in young adults. Semin Ophthalmol 2003;18:154-9.

33. Whitehead A. Meta-Analysis of Controlled Clinical Trials. Chichester, UK: Wiley; 2002:233-235.

34. Yanamandra K, Thurmon TF, Bocchini JA Jr, Kooragayala LM. Hyperhomocysteinemia and BRVO [letter]. Ophthalmology 2003;110:2069; author reply 2069.

35. DerSimonian R, Laird N. Meta-analysis in clinical trials. Control Clin Trials 1986;7:177-88.

36. Gart JJ, Zweifel JR. On the bias of various estimators of the logit and its variance with application to quantal bioassay. Biometrika 1967;54:181-7.

37. Begg CB, Mazumdar M. Operating characteristics of a rank correlation test for publication bias. Biometrics 1994;50: $1088-101$.

38. Egger M, Davey Smith G, Schneider M, Minder C. Bias in meta-analysis detected by a simple, graphical test. BMJ 1997; 315:629-34. 
39. Duval S, Tweedie R. Trim and fill: a simple funnel-plot-based method of testing and adjusting for publication bias in metaanalysis. Biometrics 2000;56:455-63.

40. Abu El-Asrar AM, Abdel Gader AG, Al-Amro SA, Al-Attas OS. Hyperhomocysteinemia and retinal vascular occlusive disease. Eur J Ophthalmol 2002;12:495-500.

41. Adamczuk YP, Iglesias Varela ML, Martinuzzo ME, et al. Central retinal vein occlusion and thrombophilia risk factors. Blood Coagul Fibrinolysis 2002;13:623-6.

42. Backhouse O, Parapia L, Mahomed I, Lee D. Familial thrombophilia and retinal vein occlusion. Eye 2000;14:13-7.

43. Blondel J, Glacet-Bernard A, Bayani N, et al. Retinal vein occlusion and hyperhomocysteinemia [in French]. J Fr Ophtalmol 2003;26:249-53.

44. Brown BA, Marx JL, Ward TP, et al. Homocysteine: a risk factor for retinal venous occlusive disease. Ophthalmology 2002;109:287-90.

45. Cahill M, Karabatzaki M, Meleady R, et al. Raised plasma homocysteine as a risk factor for retinal vascular occlusive disease. Br J Ophthalmol 2000;84:154-7.

46. Chua B, Kifley A, Wong TY, Mitchell P. Homocysteine and retinal vein occlusion: a population-based study. Am J Ophthalmol 2005;139:181-2.

47. Cruciani F, Moramarco A, Curto T, et al. MTHFR C677T mutation, factor II G20210A mutation and factor V Leiden as risks factor for youth retinal vein occlusion. Clin Ter 2003; 154:299-303.

48. Di Crecchio L, Parodi MB, Sanguinetti G, et al. Hyperhomocysteinemia and the methylenetetrahydrofolate reductase $677 \mathrm{C}-\mathrm{T}$ mutation in patients under 50 years of age affected by central retinal vein occlusion. Ophthalmology 2004;111:940-5.

49. Glueck CJ, Bell H, Vadlamani L, et al. Heritable thrombophilia and hypofibrinolysis: possible causes of retinal vein occlusion. Arch Ophthalmol 1999;117:43-9.

50. Hansen L, Kristensen HL, Bek T, Ingerslev J. Markers of thrombophilia in retinal vein thrombosis. Acta Ophthalmol Scand 2000;78:523-6.

51. Lahey JM, Tunc M, Kearney J, et al. Laboratory evaluation of hypercoagulable states in patients with central retinal vein occlusion who are less than 56 years of age. Ophthalmology 2002;109:126-31.

52. Larsson J, Hultberg B, Hillarp A. Hyperhomocysteinemia and the MTHFR C677T mutation in central retinal vein occlusion. Acta Ophthalmol Scand 2000;78:340-3.

53. Martin SC, Rauz S, Marr JE, et al. Plasma total homocysteine and retinal vascular disease. Eye 2000;14:590-3.

54. Pianka P, Almog Y, Man O, et al. Hyperhomocysteinemia in patients with nonarteritic anterior ischemic optic neuropathy, central retinal artery occlusion, and central retinal vein occlusion. Ophthalmology 2000;107:1588-92.

55. Sottilotta G, Oriana V, Latella C, et al. Role of hyperhomocysteinemia in retinal vascular occlusive disease. Clin Appl Thromb Hemost 2007;13:104-7.

56. Stanger O, Weger M, Obeid R, et al. Impairment of homocysteine metabolism in patients with retinal vascular occlusion and non-arteritic ischemic optic neuropathy. Clin Chem Lab Med 2005;43:1020-5.

57. Vine AK. Hyperhomocysteinemia: a new risk factor for central retinal vein occlusion. Trans Am Ophthalmol Soc 2000;98:493-503.

58. Vine AK. Hyperhomocysteinemia: a risk factor for central retinal vein occlusion. Am J Ophthalmol 2000;129:640-4.

59. Weger M, Stanger O, Deutschmann H, et al. Hyperhomocyst(e)inemia, but not methylenetetrahydrofolate reductase C677T mutation, as a risk factor in branch retinal vein occlusion. Ophthalmology 2002;109:1105-9.
60. Weger M, Stanger O, Deutschmann H, et al. Hyperhomocyst(e)inemia and MTHFR C677T genotypes in patients with central retinal vein occlusion. Graefes Arch Clin Exp Ophthalmol 2002; 240:286-90.

61. Lahey JM, Kearney JJ, Tunc M. Hypercoagulable states and central retinal vein occlusion. Curr Opin Pulm Med 2003;9:38592.

62. Battaglia Parodi M, Di Crecchio L. Hyperhomocysteinemia and retinal vascular occlusive disease [letter]. Eur J Ophthalmol 2003;13:500; author reply 500-1.

63. Weger M, Stanger O, Haas A. Hyperhomocysteinemia: a risk factor for central retinal vein occlusion [letter]. Am J Ophthalmol 2001;131:290-1.

64. Biousse V, Newman NJ, Sternberg P Jr. Retinal vein occlusion and transient monocular visual loss associated with hyperhomocystinemia. Am J Ophthalmol 1997;124:257-60.

65. Cabezas-Leon MM, Garcia-Montero MR, Morente-Matas P. Hyperhomocysteinemia as a risk factor for central retinal vein thrombosis in a young patient [in Spanish]. Rev Neurol 2003;37: $441-3$.

66. Hartnett ME, Laposata M, Van Cott E. Antiphospholipid antibody syndrome in a six-year-old female patient. Am J Ophthalmol 2003;135:542-4.

67. Ozdek S, Yulek F, Gurelik G, et al. Simultaneous central retinal vein and retinal artery branch occlusions in two patients with homocystinaemia [letter]. Eye 2004;18:942-5.

68. Palmowski AM, Geisel J, Herrmann W, et al. Venous thromboembolism in a young patient. Diagnosis: Retinal vein thromboembolism in mutation of the methylenetetrahydrofolate reductase gene [in German]. Ophthalmologe 1999;96: 618-9.

69. Wenzler EM, Rademakers AJ, Boers GH, et al. Hyperhomocysteinemia in retinal artery and retinal vein occlusion. Am J Ophthalmol 1993;115:162-7.

70. Cahill M, Karabatzaki M, Donoghue C, et al. Thermolabile MTHFR genotype and retinal vascular occlusive disease. Br J Ophthalmol 2001;85:88-90.

71. Dodson PM, Haynes J, Starczynski J, et al. The platelet glycoprotein Ia/IIa gene polymorphism C807T/G873A: a novel risk factor for retinal vein occlusion. Eye 2003;17: 772-7.

72. Gao W, Wang YS, Zhang P, Wang HY. MTHFR C677T mutation in central retinal vein occlusion: a case-control study in Chinese population. Thromb Res 2008;121:699-703.

73. Loewenstein A, Goldstein M, Winder A, et al. Retinal vein occlusion associated with methylenetetrahydrofolate reductase mutation. Ophthalmology 1999;106:1817-20.

74. Salomon O, Moisseiev J, Rosenberg N, et al. Analysis of genetic polymorphisms related to thrombosis and other risk factors in patients with retinal vein occlusion. Blood Coagul Fibrinolysis 1998;9:617-22.

75. Duic J, Gveric-Krecak V. Recurrent incomplete central retinal vein occlusion in a patient with hereditary thrombophilia [in Croatian]. Acta Med Croatica 2006;60:171-4.

76. Loewenstein A, Winder A, Goldstein M, et al. Bilateral retinal vein occlusion associated with 5,10-methylenetetrahydrofolate reductase mutation. Am J Ophthalmol 1997;124:840-1.

77. Chak M, Wallace GR, Graham EM, Stanford MR. Thrombophilia: genetic polymorphisms and their association with retinal vascular occlusive disease. Br J Ophthalmol 2001;85:883-6.

78. Lewis SJ, Ebrahim S, Davey Smith G. Meta-analysis of MTHFR $677 \mathrm{C}->$ T polymorphism and coronary heart disease: does totality of evidence support causal role for homocysteine and preventive potential of folate [online report]? BMJ 2005;331: 1053. Available at: http://www.bmj.com/cgi/content/full/331/7524/ 1053. Accessed December 17, 2008. 


\section{McGimpsey et al · Homocysteine, MTHFR, and Retinal Vein Occlusion: A Meta-analysis}

79. Broekmans WM, Klopping-Ketelaars IA, Schuurman CR, et al. Fruits and vegetables increase plasma carotenoids and vitamins and decrease homocysteine in humans. J Nutr 2000; 130:1578-83.

80. Samman S, Sivarajah G, Man JC, et al. A mixed fruit and vegetable concentrate increases plasma antioxidant vitamins and folate and lowers plasma homocysteine in men. J Nutr 2003;133:2188-93.
81. Davey Smith G, Ebrahim S. 'Mendelian randomization': can genetic epidemiology contribute to understanding environmental determinants of disease? Int J Epidemiol 2003;32: $1-22$.

82. Stroup DF, Berlin JA, Morton SC, et al. Meta-analysis Of Observational Studies in Epidemiology (MOOSE) Group. Meta-analysis of observational studies in epidemiology: a proposal for reporting. JAMA 2000;283:2008-12.

\section{Footnotes and Financial Disclosures}

Originally received: May 23, 2008.

Final revision: February 2, 2009.

Accepted: February 3, 2009.

Manuscript no. 2008-634

${ }^{1}$ Directorate of Ophthalmology, The Royal Victoria Hospital, The Belfast Health and Social Care Trust, Grosvenor Road, Belfast, Ireland.

${ }^{2}$ Centre for Clinical and Population Science, Queen's University Belfast Mulhouse Building, Grosvenor Road, Belfast, Ireland.

${ }^{3}$ Royal Victoria Eye and Ear Hospital, Dublin, Ireland.

${ }^{4}$ Centre for Vision Sciences, Queen's University Belfast, Institute of Clinical Science, Grosvenor Road, Belfast, Ireland.

Financial Disclosure(s):

The author(s) have no proprietary or commercial interest in any materials discussed in this article.
This study did not require external research funding. The researchers are supported by the Department for Employment and Learning Northern Ireland (JVW, CC, UC), National Health Service, and Irish Health Service (SMcG, UC, MC).

This study conforms to the following Meta-analysis of Observational Studies in Epidemiology (MOOSE) guidelines. ${ }^{82}$

Appendix 1 available online (http://aaojournal.org).

Correspondence:

Jayne V. Woodside, MA (Hons), PhD, Nutrition and Metabolism Group, Centre for Clinical and Population Science, Lower Ground Floor, Pathology Building, Grosvenor Road, Belfast, BT12 6BJ. E-mail: j.woodside@ qub.ac.uk. 


\section{Appendix 1. Proposed Reporting Checklist for Authors, Editors, and Reviewers of Meta-analyses of Observational Studies*}

Reporting of background should be

Problem definition

Hypothesis statement

Description of study outcome(s)

Type of exposure or intervention used

Study population

Reporting of search strategy should include

Qualifications of searchers (e.g., librarians and investigators)

Search strategy, including time period included in the synthesis and keywords

Effort to include all available studies, including contact with authors

Databases and registries searched

Search software used, name and version, including special features used (e.g., explosion)

Use of hand searching (e.g., reference lists of obtained articles)

List of citations located and those excluded, including justification

Method of addressing articles published in languages other than English

Method of handling abstracts and unpublished studies

Description of any contact with authors

Reporting of methods should include

Description of relevance or appropriateness of studies assembled for assessing the hypothesis to be tested

Rationale for the selection and coding of data (e.g., sound clinical principles or convenience)

Documentation of how data were classified and coded (e.g., multiple raters, blinding and interrater reliability)

Assessment of confounding (e.g., comparability of cases and controls in studies where appropriate)

Assessment of study quality, including blinding of quality assessors; stratification of regression on possible predictors of study results

Assessment of heterogeneity

Description of statistical methods (e.g., complete description of fixed or random effects models, justification of whether the chosen models account for predictors of study results, dose-response models, or cumulative meta-analysis) in sufficient detail to be replicated

Provision of appropriate tables and graphics

Reporting of results should include

Graphic summarizing individual study estimates and overall estimate

Table giving descriptive information for each study included

Results of sensitivity testing (e.g., subgroup analysis)

Indication of statistical uncertainty of findings

Reporting of discussion should include

Quantitative assessment of bias (e.g., publication bias)

Justification for exclusion (e.g., exclusion of non-English language citations)

Assessment of quality of included studies

Reporting of conclusions should include

Consideration of alternative explanations for observed results

Generalization of the conclusions (i.e., appropriate for the data presented and within the domain of the literature review)

\footnotetext{
*This study conforms to the Meta-analysis of Observational Studies in Epidemiology (MOOSE) guidelines.
} 